\title{
LA INTERVENCIÓN DE OCCIDENTE EN LAS GUERRAS ACTUALES: JUSTIFICACIÓN POLÍTICA Y RESPUESTA DE LA SOCIEDAD CIVIL
}

\author{
NOELIA BUENO GÓMEZ
}

Universidad de Innsbruck

\begin{abstract}
RESUMEN: Mientras que en los países occidentales parece existir un consenso público a favor de la defensa de los valores asociados a los Derechos Humanos, sus gobiernos ponen en marcha o intervienen en conflictos armados fuera de sus territorios que implican acciones contrarias a dichos valores. Este artículo busca desentrañar esta aparente contradicción: revisa brevemente el contexto globalizado internacional en el que tienen lugar los conflictos actuales y acude a la tradición de la guerra justa para analizar la posición de la Carta de Naciones Unidas y las justificaciones dadas por los gobiernos occidentales. Como ejemplo, se estudian algunos de los argumentos utilizados por los gobiernos estadounidenses y españoles para justificar su presencia en las guerras de Afganistán (2001) e Irak (2008), así como las respuestas de la sociedad civil.
\end{abstract}

PALABRAS CLAVE: guerra justa, relaciones internacionales, guerra de Irak, guerra de Afganistán.

\section{Western Interventions in Current Wars: Political Justification and Civil Society's Response}

ABSTRACT: On the one hand, it seems to be an agreement in Western countries in favor of values included in the Universal Declaration of Human Rights. On the other hand, Western countries initiate or intervene in armed conflicts outside their territories, which implies actions contrary to such values. This article examines this apparent contradiction: it describes briefly the international context of contemporary conflicts and it refers to the just-war tradition in order to analyze both the position of the Charter of the United Nations and the justifications given by Western countries. Moreover, the arguments used by the US and the Spanish Governments to justify their interventions in the Afghanistan (2001) and Iraq (2008) wars, and the responses of civil society are considered.

KEY WORDS: just war, international relations, Iraq war, Afghanistan war.

\section{INTRODUCCIÓN}

Diversos autores han puesto al descubierto una contradicción entre los valores públicos predominantes en las democracias occidentales, por un lado, y determinadas acciones emprendidas por los gobiernos de estos países, incoherentes con esos valores, por otro ${ }^{1}$. Se trata de los valores asociados a los Derechos Humanos,

\footnotetext{
1 Por «occidente» o "países occidentales» me refiero en este artículo a las naciones europeas y EEUU, y a su tradición cultural. En cierto modo «occidente» es un constructo teórico, como señalan Amartya Sen y otros autores postcolonialistas, y muchas de las idas asociadas a la tradición cultural occidental habían sido formuladas y desarrolladas con anterioridad o paralelamente en otros ámbitos (SEN, 2006, 121). Lejos de pretender contribuir a la «fijación con occidente» de 
particularmente el derecho a la vida, la libertad y la seguridad incluidos en el Artículo 3 de esta Declaración Universal, y el derecho a no ser sometido/a a "tratos crueles, inhumanos y degradantes» (Artículo 5). Si realmente existe un consenso en occidente en torno a este tipo de valores, si realmente estamos de acuerdo en que nos horrorizan, como señala Zygmunt Bauman, «la crueldad, la guerra, la masacre, la violación y el saqueo», entonces, ¿cómo justifican nuestros estados su participación en dichas acciones? Bauman señala uno de los casos de esta contradicción, ofreciendo la primera de las explicaciones que nos permite comprender su lógica interna: la producción y venta de armas en occidente a los países en conflicto es «promovida por los políticos y apoyada por sus votantes en nombre del balance de pagos nacional y la defensa de los puestos de trabajo»(Bauman, 1997, 64). Una primera explicación de por qué «funciona» la aparente contradicción entre valores y práctica política puede ser que no existe contradicción, porque tales valores se defienden en el plano de lo que se considera "políticamente correcto», pero no operan como la base real de la toma de decisiones de los ciudadanos ni de los representantes políticos. A la hora de votar o a la hora de promulgar una ley de control de la venta de armas, los ciudadanos y los gobiernos anteponen otros valores diferentes como el crecimiento de la economía o el bienestar material asociado a los puestos de trabajo. En otras palabras, valen más nuestra prosperidad y bienestar material que la seguridad o la vida de las víctimas de las armas que producimos y vendemos a grupos o estados violentos ${ }^{2}$. Esta doble vara de medir, que Bauman rechaza atacando la hipocresía que incorpora, viene respaldada por el hecho probado de que nos resulta mucho más fácil de aceptar la maldad de nuestras acciones si las consecuencias de éstas se encuentran lejos de nosotros. Y, más aún, por el hecho de que cuanto más lejos esté nuestra víctima, menos escrúpulos morales parecemos encontrar en hacerle más daño ${ }^{3}$.

la que habla Sen, este artículo busca reflexionar sobre una de las contradicciones subyacentes a la teoría y la práctica políticas occidentales. No quisiera, con ello, favorecer una lógica de pensamiento en la que el mundo se presente como dividido en un bloque occidental y otro que no lo es. Primero, porque eso supondría efectivamente contribuir a una fijación con occidente hija de la lógica colonialista; y segundo, porque pienso que, como han mostrado distintos sociólogos (BAUMAN, 1997; CASTElls, 1998), la metáfora de la red global que conecta a los ganadores de la globalización, junto con los flujos locales y/o el aislamiento de los excluidos, es una imagen más representativa de la sociedad mundial que la idea de los bloques.

2 En esta disyuntiva se han visto recientemente los dirigentes políticos españoles que han tenido que decidir sobre el contrato de fabricación de cinco corbetas armadas en los astilleros de Cádiz y Ferrol para vender al gobierno dictatorial de Arabia Saudí, que incumple claramente la Declaración Universal de los Derechos Humanos y está implicada en la represión y el ataque armado a otros países. Izquierda Unida y Podemos han apoyado la firma de este contrato, a pesar de haberse manifestado públicamente en contra de mantener relaciones con países que no respetan derechos fundamentales. Véase sobre este tema la noticia recogida en el periódico lamarea.com (MAESTRE, 2016) http://www.lamarea.com/2016/02/23/pan-o-ideologia-podemos-e-iu-tambien-apoyan-la-venta-de-barcos-de-guerra-a-arabia-saudi/. Consultado el 4.10.2016.

3 Tal como se puede concluir de los experimentos psicológicos llevados a cabo por Stanley Milgram en los 60. Bajo la exigencia de obediencia - pero sin más presión o amenaza que las que pueden ir unidas al respeto por la autoridad- los individuos tienden a mostrar menos escrúpulos morales a la hora de hacer daño a otros a medida que sus víctimas están más alejadas de ellos (Milgram, 1965, 62). El escritor asturiano Alejandro Casona explora la cuestión de la acción dañina a distancia desde un punto de vista literario en su obra La barca sin pescador (CASONA, 1983). 
Así, una primera respuesta a la cuestión de por qué los países occidentales intervienen en conflictos armados fuera de sus territorios es que obtienen un beneficio económico de ello, como en el caso de la venta de armas. Quizás la opinión pública no vincula las ventajas de disponer de un número de puestos de trabajo con las imágenes de la violencia lejana que nos muestra la televisión y existe una desconexión entre los valores que afirmamos defender y nuestras prioridades reales. Ahora bien, ni el comercio de armas es la única forma de intervención de occidente en las guerras actuales ni los beneficios económicos son las únicas justificaciones utilizadas. Por otra parte, los intereses, valores y argumentos de los gobiernos a menudo no coinciden con los de la sociedad civil.

El contexto de las relaciones internacionales en el que tienen lugar las guerras actuales ha dado un vuelco de 180 grados desde el final de la política de bloques de la guerra fría. Los sociólogos de la etapa post-industrial o post-moderna coinciden en destacar tanto la interconexión mundial de procesos económicos, sociales y de todo tipo, como la nueva coyuntura en que se encuentran los Estados nacionales en el contexto de la globalización. La interconexión es la base material de la globalización: los medios tecnológicos que favorecen el transporte, la comunicación y relación de procesos, mercancías y personas son los que propician que se desarrolle el mundo globalizado en el que vivimos hoy, con todas sus consecuencias positivas y negativas, con sus elites y sus excluidos. La interconexión global favorece a determinadas elites que a su vez suelen desconectarse a nivel local (las relaciones a distancia priman sobre las relaciones cercanas, comunitarias, que son con suerte el único refugio de los excluidos, como señala Bauman, 1997) y perjudica a otros sectores de población (a las víctimas de las mafias y del tráfico de personas, por ejemplo). Pero además, el protagonismo de los estados nacionales no resulta tan claro como en el pasado en el contexto de la globalización.

Manuel Castells define muy bien la paradoja a la que se ven abocados los Estados nacionales en tales circunstancias: por un lado, deben centrarse en la acción estratégica internacional conducente a un orden geopolítico mundial, y esto ocurre al margen de sus ciudadanos. Por otro lado, sin embargo, necesitan mantener y afianzar sus ideales nacionalistas, territoriales e históricos, porque en ellos se basa su identidad ante la predominancia generalizada de los flujos globales ${ }^{4}$. ¿Cómo someterse a las demandas de un «sistema global interactivo» en el que se delega necesariamente soberanía, y a la vez mantener de puertas para adentro la idea de identidad nacional? (Castells, 1998, 338)

La primera de las claves que hemos de tener en cuenta es, por tanto, el contexto internacional de interdependencia de los estados vinculada al proceso de globalización. Como reacción a este contexto encontramos las tendencias, a veces radicales, del nacionalismo (en su extremo, el intento de construir comunidades basadas en la

4 También Habermas $(1999,99)$ piensa que aunque el capitalismo, que desde el principio adoptó dimensiones planetarias, contribuyó en un primer momento a la consolidación de los estados nacionales, estos han perdido (al desnacionalizarse la economía política nacional) tanto el dominio sobre las condiciones de producción que les proporcionaban ventajas tributarias, como el control sobre las empresas. Para Habermas, el proceso de globalización amenaza la identidad del Estado nacional, que como reacción se aferra a ésta. Ante este panorama, Habermas considera imprescindible la creación de autoridades supranacionales. 
idea de una identidad colectiva excluyente, cerrada) y el fundamentalismo religioso (cristiano y musulmán), mencionando sólo dos de la lista ofrecida por Castells $(1998,34)$. Estos dos movimientos constituyen reacciones frente a la tendencia globalizadora que parece amenazar las identidades colectivas tradicionales. En ellos encontramos el origen de algunos de los conflictos armados de nuestro tiempo. En el hecho de formar parte de un mundo globalizado, donde los estados-nación son más bien agentes estratégicos que agentes soberanos, y en la predominancia de intereses económicos en un entorno capitalista encontramos el origen de muchos otros. Además, las relaciones internacionales son ya algo más que relaciones «entre las naciones» porque se han incorporado otros agentes. Si sumamos esto al hecho de la interdependencia internacional, fruto de la interconexión (que genera también una globalización de los riesgos, como señala Beck, 1988) encontramos que un conflicto que estalla en un punto del planeta puede haber sido propiciado por intereses económicos o de otro tipo procedentes del otro lado del globo, o incardinados en una red que lo circunda. Más aún, dicho conflicto puede verse acrecentado por la inclusión de valores territoriales o nacionalistas, como los mencionados anteriormente, y por la adquisición de armas producidas en países lejanos. Pero por más que se distribuyan las responsabilidades, éstas no se disuelven. En esta red de interconexiones, occidente tiene que ver con el origen, el mantenimiento o la incentivación de las guerras actuales en varios niveles y de diversas maneras, que no siempre coinciden con la acción de los estados nacionales como agentes.

La segunda de las claves para entender la justificación de la participación o ausencia de los países occidentales en los conflictos de terceros países tiene que ver con la calidad de los argumentos utilizados y con el tipo de valores invocados. La Declaración Universal de los Derechos Humanos es partidaria de la educación para la paz, pero no rechaza toda violencia. De hecho, es posible invocarla para justificar una intervención armada, siempre y cuando ésta se encamine a la protección de los valores defendidos por la Declaración. Esta cuestión nos conduce a la pregunta por la posibilidad de una guerra justa.

\section{LA TEORÍA DE LA GUERRA JUSTA}

Aunque existen precedentes en la antigüedad clásica y corrientes de pensamiento sobre la guerra justa procedentes de otras tradiciones, la teoría de la guerra justa procede, en la tradición de pensamiento occidental, de los filósofos y teólogos católicos Agustín de Hipona (s. v) y Tomás de Aquino (s XIII). Posteriormente fue completada por los españoles Francisco de Vitoria y Francisco Suárez (xvI) y por la escuela de pensamiento originada en torno a Hugo Grocio (s. XVIII). El problema moral al que se enfrentaron, primero San Agustín, considerado el último de los filósofos antiguos y el primero de los medievales, y ocho siglos después, Santo Tomás, fue el siguiente: ¿puede la guerra justificarse moralmente? Aunque para Agustín de Hipona la justicia era una especie de ideal regulativo que por su perfección podía alcanzarse por completo en la ciudad de Dios pero no en la ciudad temporal, las formas de gobierno podían regularse de acuerdo con determinados principios morales que se encaminasen hacia esa justicia como si fuese alcanzable. 
En definitiva, la cuestión era cómo justificar desde el cristianismo unas acciones basadas en la violencia cuando el mensaje del Nuevo Testamento iba asociado a valores contrarios, como el pacifismo y el perdón. Agustín propuso una serie de criterios para delimitar las condiciones de la guerra justa relativos a la autoridad de los iniciadores de la guerra, las causas y los objetivos de la intervención. Tomás de Aquino refinó estos criterios, que quedaron formulados de la siguiente manera: una guerra, para poder ser calificada de justa, debería proceder de una autoridad legítima; debería venir originada por una causa justa y debería estar guiada por una intención recta (Butler, 2012, 24). Ambos autores asumieron, sin embargo, que el recurso a la guerra incluye consecuencias indeseables y contrarias a la justicia, por lo que la guerra nunca puede constituir un medio completo o perfecto de alcanzar la justicia. Probablemente, la aportación más decisiva de Suárez en lo sucesivo fue la de añadir a lo anterior un derecho universal de los pueblos y las naciones a su legítima defensa. El derecho a la legítima defensa ya había sido considerado por Agustín de Hipona, y después por Tomás de Aquino como una causa justificada para la guerra. La novedad radica, en el caso de Suárez, en atribuir este derecho a todos los pueblos (Butler, 2012, 24).

Por su parte, la escuela de Hugo Grocio sentó las bases del derecho internacional, retomando la tradición iniciada por la Escuela de Salamanca, desde una perspectiva iusnaturalista. El debate pasaba así del ámbito moral en el contexto teológico al ámbito del derecho y la legislación internacional. En cierto sentido se puede decir que Hugo Grocio comenzó el proceso de secularización de la cuestión de la guerra justa. Como sus predecesores, Hugo Grocio piensa que la guerra no es injusta bajo determinadas circunstancias como las ya recogidas en la tradición previa a él $(2001,21)$. Grocio se detiene particularmente en lo que pueden considerarse «causas justas» de la guerra, como la legítima defensa, la protección de la seguridad y la vida, y los recursos para mantenerla (considerados derechos naturales). De iure belli ac pacis (1625) es también un tratado donde se discuten y regulan las normas que deberían regir en caso de contienda, como el derecho de conquista o el tratamiento de los prisioneros de guerra, y se anticipan algunas cuestiones que en la actualidad son objeto de estudio de la justicia transicional, como el derecho a las honras fúnebres de las víctimas. La reflexión y discusión sobre la teoría de la guerra justa no decayó en los siglos sucesivos, aunque a menudo fue utilizada más como medio para justificar intervenciones armadas que para justificar las restricciones a dichas intervenciones. Es decir, las justificaciones que los teóricos del derecho y los moralistas habían esgrimido para apoyar el uso internacional de la fuerza han servido a menudo más como excusas para apoyar dicho uso que como justificaciones, con consecuencias prácticas, para limitar efectivamente la violencia.

Con todo, tanto los discursos pacifistas como los discursos que limitan, al menos parcialmente, la justificación del uso de la violencia han perdurado y han cristalizado en la creación de instituciones internacionales como la Organización Internacional de Naciones Unidas. Las ideas expresadas por Inmanuel Kant en Sobre la paz perpetua (1795) inspiraron, junto con la brutal experiencia de dos guerras mundiales en el siglo xx, la firma de la Carta de Naciones Unidas. Sobre la paz perpetua es una exhortación a los Estados del mundo para que asienten las bases de una paz duradera en la que las relaciones internacionales se ajusten al derecho y no al imperio del más fuerte basado en el uso de la violencia. Kant insiste en que no se 
trata de proponer un gobierno mundial, que acabaría por someter a los diferentes pueblos, sino de un estado de convivencia pacífica internacional basado en la «libre federación de los pueblos» (Kant, 2011, 10). La otra idea clave del influyente tratado kantiano es que la paz a la que apela no es un tipo de paz «transitoria», como la que media entre dos guerras, sino un estado de convivencia deseado, esperado, y diseñado por el filósofo para la humanidad. Por eso, establece las directivas por las que, tanto en caso de guerra como en caso de haberse firmado un tratado de paz, deben regirse las relaciones entre los Estados. Así, defiende que un tratado de paz debe firmarse sin reserva alguna que pueda dejar vías abiertas hacia una posible nueva guerra y durante el transcurso de un conflicto armado no deben utilizarse «hostilidades» que amenacen una paz futura. Es decir, la paz aparece siempre en el horizonte de los fines que se desean conseguir y además es un fin con pretensiones de perpetuidad, sin que dicha perpetuidad se base, como subraya con ironía el filósofo, en la paz eterna de los cementerios. Kant se adelanta así a las posibilidades destructivas de una guerra atómica, al justificar la norma que prohíbe la guerra total dos siglos antes de que ésta fuera técnicamente posible.

El «espíritu» de La paz perpetua de Kant es el mismo que anima la Carta de las Naciones Unidas, aprobada en 1945. En su primer artículo afirma que es objetivo de las Naciones Unidas:

«Mantener la paz y la seguridad internacionales, y con tal fin: tomar medidas colectivas eficaces para prevenir y eliminar amenazas a la paz, y para suprimir actos de agresión u otros quebrantamientos de la paz; y lograr por medios pacíficos, y de conformidad con los principios de la justicia y del derecho internacional, el ajuste o arreglo de controversias o situaciones internacionales susceptibles de conducir a quebrantamientos de la paz».

De nuevo, no obstante, la Carta de las Naciones Unidas deja abierta la puerta a intervenciones armadas de los estados miembros, siempre que se orienten al fin último que, como en el tratado kantiano anteriormente citado, debe ser explícitamente la paz:

«Los Miembros de la Organización arreglarán sus controversias internacionales por medios pacíficos de tal manera que no se pongan en peligro ni la paz y la seguridad internacionales ni la justicia» (Artículo 3).

Asimismo, la Carta trata de que la única autoridad competente para legitimar una intervención armada sea la ONU misma:

«Si el Consejo de Seguridad estimare que las medidas de que trata el Artículo 41 pueden ser inadecuadas o han demostrado serlo, podrá ejercer, por medio de fuerzas aéreas, navales o terrestres, la acción que sea necesaria para mantener o restablecer la paz y la seguridad internacionales. Tal acción podrá comprender demostraciones, bloqueos y otras operaciones ejecutadas por fuerzas aéreas, navales o terrestres de Miembros de las Naciones Unidas» (Artículo 42).

Implícitamente, la Carta de las Naciones Unidas incluye un ideario de «guerra justa», en la línea de la tradición que he explicado. El viejo adagio «Si vis pacem para bellum» ya no sirve como principio regulador en el contexto actual, al menos no en un plano moral. La paz constituye un fin en sí misma, un fin que debe ser perseguido por medios pacíficos. Más aún, se ha señalado cómo la Carta de Naciones 
Unidas es un intento encaminado a la formulación de la auto-defensa como única causa justa de guerra (Butler, 40). En el próximo epígrafe mostraré cómo las intervenciones militares recientes de Estados occidentales en terceros países han venido justificándose por referencia a estas normas internacionales. No obstante, estas justificaciones se han asemejado, en algunos casos, más a excusas de cara a encubrir intereses no vinculados a los preceptos de la guerra justa que a justificaciones moral y legalmente aceptables (con arreglo al derecho internacional) de acuerdo con dichos criterios. Algunos autores destacan que ésta ha sido la tónica general desde la Segunda Guerra Mundial, cuando las justificaciones propias de la tradición de la guerra justa han servido de manera paradigmática para respaldar moralmente la intervención de los aliados (en especial el principio de la causa justa y el de la recta intención), más que para refrendar o limitar su uso de la violencia (Butler, 39).

Revisemos, para concluir este epígrafe, los criterios que, en la tradición mencionada, permitirían justificar una guerra ${ }^{5}$ :

1) Causa justa. Se consideran causas justas: la autodefensa (que podría incluir la autodefensa anticipada, contra actos violentos previstos de manera inminente); la defensa de inocentes; la reclamación de bienes, personas o territorios ilegalmente sustraídos; el castigo de actos perniciosos contra la humanidad.

2) Autoridad competente. Tradicionalmente, es la autoridad soberana, legítima. En el contexto de un gobierno democrático, los ciudadanos eligen a sus gobernantes y, mediante diversos mecanismos de participación (referéndum, consultas...) hacen valer su posición sobre las decisiones políticas, incluyendo las decisiones encaminadas a iniciar un conflicto armado. Más arriba he mencionado cómo la Carta de Naciones Unidas se inclina hacia una situación en la que sea la propia ONU la única autoridad legitimada para justificar cualquier intervención armada en un conflicto internacional.

3) Intención recta. La motivación que impulsa el inicio de las hostilidades debe ser justa.

4) Esperanza razonable de éxito.

5) Proporcionalidad de los fines deseados y los medios empleados para conseguirlos.

A esta lista se ha añadido también el principio de que la guerra debe ser el último recurso, después de haber tratado de resolver el conflicto en cuestión mediante recursos pacíficos y otras medidas de presión como sanciones económicas (contempladas también en la Carta de Naciones Unidas).

En los dos apartados siguientes se ofrecen dos ejemplos que ponen de manifiesto el «uso» que los Estados participantes en los conflictos armados de Afganistán e Irak han hecho de la referencia a la tradición de la guerra justa, así como la respuesta de la sociedad civil. No se pretende realizar un estudio exhaustivo, sino poner en funcionamiento una pauta de análisis que podría continuar aplicándose posteriormente de manera más extensa.

\footnotetext{
5 Esta lista de criterios está elaborada a partir de Butler (2012, 81).
} 


\section{Justificación política y RESPUESTA de la Sociedad civil En EE. UU. y España a la} Guerra de Afganistán

La guerra de Afganistán comenzó el 7 de octubre de 2001, cuando Estados Unidos y Reino Unido iniciaron los bombardeos sobre el país. Los ataques ocurrían menos de un mes después de los atentados del 11 de septiembre, perpetrados por la red de terrorismo internacional Al Qaeda. La denominada Operación Libertad Duradera tenía por objetivo derrotar el régimen talibán y desmantelar Al Qaeda. A los ataques aéreos siguió una ofensiva militar terrestre (en la que participaron otros estados aliados) que culminó en el derrocamiento del gobierno talibán. Se ha señalado que la Operación Libertad Duradera no poseía plena legitimidad internacional (Del Viso, 2010, 110), aunque es cierto que el Consejo de Seguridad de la ONU había emitido dos Resoluciones relacionadas con los ataques del 11-S en las que se reconocía el derecho a la legítima defensa (Resolución 1368 y 1373 de 2001), como menciona Hinojosa $(2008,2)$. Tras la caída del régimen talibán, se creó la Fuerza Internacional de Asistencia para la Seguridad, esta vez autorizada expresamente por la ONU (Resolución 1386 de 2001), con el fin de afianzar el nuevo gobierno del país, tratando de aunar la lucha contra los grupos terroristas aún vigentes con la consolidación de la democracia. Sin embargo, la crisis continuó largamente: insurgencia, corrupción del gobierno, narcotráfico, descontento social (Del Viso, 2010, 110). La Fuerza Internacional de Asistencia para la Seguridad ha procedido a la retirada de las tropas internacionales, entre las que hubo tropas españolas hasta septiembre de 2013, aunque la OTAN mantiene efectivos para reforzar la seguridad del país.

Como hemos visto, las dos primeras resoluciones de la ONU que se referían a la inminente reacción de EE. UU. tras los atentados del 11 de septiembre de 2001 esgrimían el argumento de la legítima defensa para respaldar indirectamente dicha intervención, aunque se hicieron necesarias varias precisiones para adecuar uno de los antiguos principios de la guerra justa a la nueva coyuntura internacional ${ }^{6}$. Por ejemplo, el hecho de que la agresión inicial hubiera sido cometida en territorio estadounidense, no por otro país, sino por un grupo radical privado. Así, hubo que probar que el gobierno afgano estaba efectivamente amparando a Al Qaeda (siendo su cómplice) antes de emplear la justificación de que atacar Afganistán era una «defensa legítima». Sin embargo, la apelación a ésta no fue el principal argumento justificativo empleado en los discursos que el gobierno estadounidense de la época, presidido por George W. Bush, utilizó para defender y apoyar moralmente su decisión de atacar Afganistán. Por el contrario, Bush basó su discurso justificativo de los ataques a Afganistán en la idea de que EEUU tenía una responsabilidad con el combate y castigo del «mal»y, por otro lado, en la idea de que el régimen Talibán era de tipo autoritario, y por eso merecía ser derrocado y sustituido por un gobierno democrático, también por el bien de la sociedad civil afgana (Butler, 2012, 207 209). En ambos casos, EEUU aparece no como víctima de un ataque frente al que debe defenderse, sino como adalid de la democracia, e incluso del «bien» y de la

6 Sobre los detalles de la legitimación internacional de dicha intervención, véase Hinojosa (2008). 
civilización ${ }^{7}$. A menudo, en sus discursos Bush insiste en que el pueblo afgano no es el objetivo de los ataques estadounidenses, como tampoco lo es el Islam (2001c). El presidente insiste incluso en que el ejército está «alimentando» al hambriento pueblo afgano, en alusión a los lanzamientos de alimentos que se produjeron simultáneamente a los bombardeos (Bush 2001d). La sociedad civil reaccionó críticamente ante la paradoja que suponía lanzar primero bombas y después alimentos.

La justificación de los sucesivos gobiernos españoles de la presencia de las tropas del país en Afganistán se basó, durante el gobierno de José María Aznar, en argumentos que sintonizaban bien con los empleados por el presidente norteamericano de la época (Del Viso, 114). También el gobierno de Aznar y el sucesivo de José Luis Rodríguez Zapatero utilizaron otro tipo de argumentos: el de la responsabilidad del país para con sus socios internacionales, en el contexto de unas acciones que habían sido legitimadas por el apoyo de la ONU a la Fuerza Internacional para la Asistencia de la Seguridad. El hecho de atribuir a esta misión de la ONU una función pacificadora generó la discusión lingüística sobre si debería o no denominársele "guerra», a pesar del incremento de la violencia tras su implantación. En cualquier caso, los argumentos empleados para declararla justa han sido, como hemos visto, la defensa de los inocentes (el pueblo afgano sometido a un gobierno autoritario), la legitimación de la autoridad (el amparo de la ONU) y la intención recta (en la que se podría incluir la lucha contra el terrorismo internacional y la función democratizadora).

Sin embargo, la población civil no siempre aceptó estos argumentos ni dejó de considerarlos, en ocasiones, como «excusas» para la violencia en lugar de limitaciones morales al uso de la misma. Por un lado, la legitimidad internacional de la Operación Libertad Duradera es dudosa, al no haberse producido una autorización explícita de la ONU. Por otro lado, la opinión pública, como se puede valorar a través de los debates en los medios de comunicación, se preguntaba por qué no se procuró una misión democratizadora e impulsora del desarrollo del país antes de que la situación humanitaria en Afganistán fuera tan grave (si es que éste era el verdadero fin de la intervención) y rechazaba eufemismos como el incluido en la expresión «daños colaterales», que oculta el sufrimiento humano atroz intrínseco a cualquier guerra. Por otra parte, sin embargo, el envío de tropas de países occidentales a Afganistán ha tenido un considerable apoyo ciudadano (Del Viso, 130), mayor en EE. UU. que en Europa, donde además dicho apoyo ha venido unido a la idea de que la presencia de las tropas debería enfocarse a la reconstrucción del país más que al combate de los grupos talibanes. En EE. UU. el apoyo al combate de los talibanes era el doble que en Europa.

Según diversos estudios recogidos por el Barómetro del Real Instituto Elcano (2004), el 75\% de los españoles pensaban que las intenciones manifestadas por EE. UU. en su lucha contra el terrorismo no eran sinceras, y el $67 \%$ que EE. UU. sólo quería controlar el petróleo de Oriente Próximo (Del Viso, 130). Estas opiniones arrojan la sospecha de que la credibilidad en los argumentos justificativos de la intervención militar en Afganistán no era muy alta, lo cual en el contexto

7 Véanse, sobre todo, los discursos de BusH 2001a y 2001b. En el último define la lucha contra el terrorismo como la «lucha del mundo» y la civilización (no sólo de América) por la libertad. 
democrático merma la legitimidad de tales intervenciones, al menos en lo que se refiere al apoyo ciudadano.

No hay duda de que el modo en el que se construye el debate político y social en torno a una intervención armada depende, entre otros factores, del modo en que se informa acerca de dicha intervención. En este sentido, algunos estudios muestran un cambio de tendencia entre el modo en que se ha informado del impacto de guerras recientes como la de Irak y cómo se había informado acerca de la Primera Guerra del Golfo. Mientras que en la Primera Guerra del Golfo el 75\% de las informaciones emitidas procedían de agencias estadounidenses, en la Segunda Guerra del Golfo o Guerra de Irak ha habido una pluralidad de fuentes de información mucho más amplia, incluyendo la presencia de periodistas en el terreno y la incorporación de la cadena qatarí Al-Jazeera (Martín, 2007, 580-581). La cobertura de la guerra de Irak no ha escatimado en imágenes del sufrimiento humano provocado por la guerra y en multitud de relatos sobre la misma, que recogían diversos puntos de vista (no solamente el estadounidense de la «lucha contra el terror» sino por ejemplo el punto de vista de que se trataba de una "guerra de invasión», entre otros). Éstas son precisamente las imágenes que «horrorizan» al espectador occidental, las que llega a asociar al envío de tropas de su propio país a un lugar que, aunque lejano, entra a través de la televisión y la prensa hasta el interior del salón de cada casa. Aunque una mayor involucración ciudadana podría esperarse si su rechazo moral a estas intervenciones armadas fuese tan fuerte como el horror que causan estas imágenes, no es cierto que la sociedad haya permanecido indiferente a ellas $^{8}$. Así ha quedado probado, al menos, en el caso de las manifestaciones masivas que se produjeron en España en contra de la guerra de Irak.

\section{Justificación Política y RESPUESTA de la SOCIEDAd CIVIL EN EE. UU. y EsPaÑa a La Guerra de IraK}

La Guerra de Irak, también llamada Segunda Guerra del Golfo, ha llegado a considerarse uno de los conflictos internacionales recientes más graves, tanto por la crisis estratégica que representa como por la división que generó entre los países de la OTAN o los desafíos que supuso para el sistema de seguridad de la ONU (Hinojosa, 2008, 5). La Guerra de Irak comenzó el 20 de marzo de 2003 cuando EE. UU., apoyado por Reino Unido (y con el apoyo no armado de otros países) comenzó sus ataques. Sin embargo, es importante tener en cuenta la continuidad de este conflicto con la Primera Guerra del Golfo, que había culminado en los 90 con la intervención armada internacional, amparada por la ONU (Resolución 678 de 1990), para liberar Kuwait de la invasión iraquí. Desde el final de la Primera Guerra del Golfo se habían producido bombardeos de EE. UU. y Reino Unido en Irak en otras ocasiones. Tras los ataques de 2003 de las tropas estadounidenses y británicas, primero aéreos y después por tierra, las primeras imágenes que trataban

8 El papel de los medios de comunicación en la difusión de las horrorosas imágenes de las guerras y las consecuencias de dicha difusión aparece discutido en Alba Rico (2007, 89-103) y SONTAG (2004). 
de escenificar la caída del régimen de Saddam Hussein llegaban a todas las televisiones del mundo. El 9 de abril de 2003, soldados estadounidenses derribaban una enorme estatua del exdirigente iraquí en la plaza Firdos de Bagdag, aparentemente en medio de una muchedumbre de iraquíes que los vitoreaba como a sus liberadores. Sin embargo, ni el «error» del soldado estadounidense que envolvió la cabeza del dictador con la bandera de su país (error abucheado por los iraquíes presentes en la plaza, y subsanado por el reemplazo de esta bandera por la enseña nacional iraquí) ni el hecho de que en la plaza no hubiera más de unas 200 personas, controladas por los marines americanos, parecen respaldar la idea de que estaban allí en calidad de liberadores (Rampton y Stauber, 2003, 1-3). El 1 de mayo de 2003, el entonces presidente estadounidense G. W. Bush anunciaba el final de los principales ataques contra Irak, sin que ello supusiera el final de la violencia, que había de continuar aún en los años siguientes (y recientemente se ha recrudecido tras los ataques aéreos iniciados por EE. UU. y una coalición de países el 10 de agosto de 2014 contra el grupo terrorista Estado Islámico).

El 22 de mayo de 2003, el Consejo de Seguridad de la ONU emitió una resolución (1483) en la que se regulaba la situación de las potencias que ocupaban Irak, dando a las Naciones Unidas una función humanitaria y de reconstrucción civil del país. Como subraya Hinojosa (2008, 7-8), otras dos resoluciones de la ONU son decisivas a la hora de evaluar la legitimidad internacional de estos ataques: la Resolución 1500 de 2003, que respalda la creación de un gobierno representativo, y la Resolución 1511 (2003) que autoriza el uso de la fuerza a los aliados dirigidos por EE. UU. para mantener la seguridad y la estabilidad en el país. Del minucioso análisis realizado por Hinojosa se sigue, no obstante, que estas resoluciones posteriores a la invasión no constituyen una legitimación del uso de la fuerza previo a las mismas, ni un respaldo del ataque inicial de EE. UU. y Reino Unido. Tras la emisión de estas resoluciones, España, bajo el gobierno de José María Aznar, envió un contingente de tropas a Irak, que llegaron a su destino a partir del 30 de julio de $2003^{9}$. Saddam Hussein fue capturado en 2003 y ejecutado por crímenes contra la humanidad el 30 de diciembre de 2006. En medio de escándalos como el de Abub Ghraib y la crisis humanitaria, la ocupación continuó hasta que en 2011 las tropas estadounidenses se retiraron definitivamente del país, siendo presidente Barak Obama, sin que esto haya supuesto el final de la violencia y los atentados en la región. Las tropas españolas se habían retirado en 2004, como resultado de la promesa electoral realizada por el PSOE justo antes de llegar al poder. José Luis Rodríguez Zapatero respondía así a las movilizaciones masivas que se habían producido en España en contra de la Guerra de Irak. En realidad las movilizaciones, que alcanzaron su punto culminante en febrero de 2003, habían tenido lugar por todo el mundo, en lo que se ha denominado la "primera manifestación global de la historia» ${ }^{10}$.

¿Qué justificaciones se habían alegado en favor de la invasión de Irak? En su discurso a la nación del 19 de marzo de 2003, el presidente G. W. Bush justificaba

\footnotetext{
9 Para una cronología de la situación de las tropas españolas en Irak, véase el reportaje de El Mundo en http://www.elmundo.es/elmundo/2004/04/18/espana/1082310065.html, consultado el 04.10.2016.

10 Comas (2003). http://elpais.com/diario/2003/02/16/internacional/1045350001_850215.html, consultado el 5.10.2016.
} 
la guerra mediante los siguientes argumentos: proceder al desarme de Irak, liberar al pueblo iraquí de su gobierno tiránico y defender al mundo de un grave peligro (el de las armas de destrucción masiva) ${ }^{11}$. La primera de las justificaciones se refería indirectamente a la resolución 687 (1991) de la ONU, que había establecido el desarme de Irak tras el final de la Primera Guerra del Golfo, así como una serie de inspecciones del organismo internacional. Sin embargo, aunque la resolución 1441 (2002) daba la «última oportunidad» a Irak para cumplir con el desarme, advirtiendo de que el incumplimiento tendría "graves consecuencias», la ONU no había resuelto llevar a cabo dichas consecuencias, lo que EE. UU. asumió como tarea propia ${ }^{12}$. Al aludir al desarme del país, por tanto, el presidente Bush trataba de dar una apariencia de legitimidad internacional al ataque (legitimidad que vendría supuestamente apoyada por la participación o apoyo de una lista de países aliados). Además, mencionar las armas de destrucción masiva suponía dar forma a un tipo de «legítima defensa» que ha sido denominada «legítima defensa preventiva» (Hinojosa 2008, 9), según la cual es posible defenderse de manera anticipada de amenazas que se prevén inminentes. Sin embargo, el que este ataque no estuviera explícitamente respaldado por una resolución de la ONU impide que haya sido respetado el principio de la guerra justa de la «autoridad competente», en las circunstancias del presente orden internacional.

La justificación de liberar al pueblo iraquí puede considerarse una apelación a la causa justa de la guerra (la defensa de inocentes) y una manifestación de la recta intención de la intervención (subrayada además por la idea de que las tropas estadounidenses luchan por la libertad, también por la libertad de otros, y de que EE. UU. no tiene otros intereses en la zona, algo que Bush destaca explícitamente en este discurso). En el discurso de Bush hay también una referencia explícita a la esperanza de éxito, y una justificación de los medios utilizados en virtud de la intención de que el conflicto sea breve.

El discurso presidencial de justificación se vio con toda seguridad apoyado por el 66\% de los estadounidenses que, de acuerdo con una encuesta realizada a finales de 2002, pensaba que Saddam Hussein había estado involucrado en los ataques del 11-S (Rampton y Stauber, 2003, 78). Para los autores de este estudio, dicha creencia, así como la creencia generalizada de la población estadounidense en la veracidad de la existencia de tales armas de destrucción masiva se debían a la campaña

11 Discurso del Presidente Bush a la Nación de 19 de marzo de 2003. http://georgewbushwhitehouse.archives.gov/news/releases/2003/03/20030319-17.html, consultado el 5.10.2016.

12 Para Rafael L. Bardají una nueva resolución que justificara el uso de la fuerza no habría sido necesaria porque la resolución 1441 dejaba claras la posición de la ONU y las obligaciones de Irak. Para Bardají hay precedentes de que uno o varios países hagan valer resoluciones anteriores de la ONU sin estar plenamente refrendados por este organismo internacional, lo que respaldaría la actuación de EE. UU. en Irak. Aunque considera justificada la guerra contra Irak sin una nueva resolución, piensa que era la misma ONU quien más la necesitaba, con el fin de hacer valer las consecuencias de sus propias normas. Bardají afirma que «son países y gobiernos concretos los que se sientan alrededor de la mesa de las Naciones Unidas, no jueces interpretando un código internacional que no existe» (BARDAJí, 2003, 141-142), lo cual sin duda es cierto. Sin embargo, los países y gobiernos concretos sentados alrededor de una mesa son el mejor mecanismo que tenemos a la hora de tomar decisiones sobre la guerra y la paz, mejor sin duda (más democrático) que un solo país tomando las riendas de la política internacional. 
propagandística del propio gobierno estadounidense para suscitar el apoyo popular hacia la guerra. Sin embargo, justo antes de la ocupación de Irak, los inspectores de Naciones Unidas no habían hallado tales armas en Irak, ni tampoco pruebas de su existencia, y tras la ocupación, EE. UU. y los estados que lo apoyaron no probaron la existencia de dichas armas ni de la relación entre el régimen de Saddam Hussein con Al-Qaeda (Hinojosa 2008, 9). Las mentiras de los dirigentes estadounidenses y británicos crearon un considerable revuelo internacional, que desembocaría en las manifestaciones masivas mencionadas anteriormente.

En el caso español, el presidente del momento, José María Aznar, elaboró una argumentación justificativa del apoyo del país a EE. UU. en la misma línea de la propuesta por Bush: alusión a las armas de destrucción masiva, al terrorismo y sus amenazas globales, y en este caso también, una explícita conexión entre el régimen iraquí y los atentados del 11-S ${ }^{13}$. Sin embargo, el apoyo a la invasión fue mucho menor en España que en EE. UU., como prueban las manifestaciones populares en su contra, que podrían haber completado tres millones de participantes entre Madrid y Barcelona el día 16 de febrero de 2013 (Comas, 2003), y los datos de algunas encuestas que revelan que el $80 \%$ de la población española se oponía a la guerra (Rampton y Stauber, 2003, 118; Noya, 2003, 65).

\section{ConcLusión}

Si retomamos ahora la cuestión planteada al principio de este estudio (¿existe una contradicción entre ciertos valores públicos predominantes asociados a los DD. HH. y las intervenciones armadas de occidente?) podemos concluir que, por un lado, esta pregunta pone de manifiesto un dilema o una hipocresía moral: la producción de armas que da trabajo aquí se pone al servicio del atentado contra la vida y la seguridad de otras personas en terceros países. Por otro lado, es cierto que la tradición de la guerra justa ha encontrado una fuerte implantación en la actualidad, al institucionalizarse en la ONU y sus organismos internacionales de gestión. La Carta de Naciones Unidas y la Declaración Universal de Derechos Humanos son la prueba de que existe cierto consenso y voluntad internacional de compromiso con la paz y otros valores asociados a ella. Los gobiernos occidentales que comenzaron las guerras de Afganistán e Irak (EE. UU. y Reino Unido, apoyados por otros países aliados) han utilizado argumentos tomados de la tradición de la guerra justa: necesitaban ofrecer una explicación moral de sus acciones violentas. De hecho, según la normativa internacional actual pueden defenderse mediante la violencia valores contrarios a la misma, siempre y cuando efectivamente estén probadas la «recta intención» y la "causa justa» (como la autodefensa). En sintonía con la tradición de la guerra justa, subyace la idea de que el fin (la defensa de valores como la vida, la libertad y la seguridad) justifica los medios (la intervención violenta se produce con el objetivo de destruir a quienes amenazan la vida, la libertad y la seguridad de otros o en virtud del principio de legítima defensa).

13 Congreso de José María Aznar ante el Congreso de los Diputados el 5 de febrero de 2003. 
Sin embargo, ni la primera intervención armada en Afganistán (la llamada Operación Libertad Duradera) ni los ataques de 2003 que dieron comienzo a la guerra de Irak estaban respaldados por resoluciones de la ONU (si bien en el primer caso existían resoluciones relacionadas con los atentados del 11-S que justificaban el derecho a la legítima defensa y en el segundo caso la resolución 1441 suponía un ultimatum para el régimen de Saddam Hussein). Aunque las guerras de Irak y Afganistán se han justificado apelando a los preceptos de la normativa internacional, dichas justificaciones han operado, a menudo, a modo de excusas para intervenir de forma violenta con otros objetivos que no encajan en los preceptos de la guerra justa (como objetivos económicos, por ejemplo, en los que no he podido detenerme). Además, las justificaciones empleadas por los gobiernos de los países que iniciaron las guerras fueron desigualmente creídas y apoyadas por los ciudadanos (la justificación política esgrimida no resultó convincente para la sociedad civil). Según los estudios, la credibilidad habría sido mayor en EE. UU. que en Europa, lo cual podría deberse a las fuertes campañas propagandísticas desarrolladas en el país americano (Rampton y Stauber 2003). Finalmente, no conviene olvidar que millones de ciudadanos de todo el mundo reaccionaron a lo que se revelaron como falsas excusas para justificar la invasión de Irak. En España, las manifestaciones ciudadanas alcanzaron dimensiones históricas y, junto con los atentados terroristas del 11 de marzo de 2004 en Madrid, podrían haber influido en los resultados electorales del 19 de marzo, que dieron la victoria al PSOE de Rodríguez Zapatero - quien había prometido sacar las tropas españolas de Irak. Las intervenciones armadas perdían así legitimidad tanto desde la autoridad supranacional como desde la base ciudadana.

\section{Bibliografía}

Alba Rico, S., Capitalismo y nihilismo. Dialéctica del hambre y la mirada, Madrid, Akal, 2007. Aznar, J. M., Discurso del presidente del gobierno ante el Congreso de los Diputados, de 5 de febrero de 2003.

BARDAJí, R., «Irak, Naciones Unidas y el uso de la fuerza», en Bardají (ed.), Irak: Reflexiones sobre una guerra, Real Instituto Elcano de Estudios Internacionales y Estratégicos, 2003, 137-145.

Bauman, Z., Posmodernity and its Discontents, Oxford, Polity Press, 1997.

BEcK, U., La sociedad del riesgo global, Madrid, Siglo XXI Editores, 1988.

Bush, G. H. W., Statement by the President in his Address to the Nation, 11 de septiembre de 2001a.

Bush, G. H. W., Address to a Joint Session of Congress and the American People, September 20, 2001b.

Bush, G. H. W., Remarks to the March of Dimes Volunteer Leadership Conference, 12 de octubre de 2001c.

Bush, G. H. W., Remarks to Employees of the Dixie Printing and Packaging Corporation in Gen Burnie, Maryland, 24 de octubre de 2001d.

Bush, G. H. W., Address to the Nation, March 19, 2003.

ButLer, M. J., Selling a "Just» War. Framing, Legitimacy, and US Military Intervention, New York, Palgrave Macmillan, 2012.

Carta de las Naciones Unidas, 1945.

Casona, A., La barca sin pescador, Madrid, Edaf, 1983. 
CASTells, M., La era de la información, vol. 2. Madrid, Alianza, 1998.

Comas, J., «Clamor mundial contra la guerra.» El País, 16 de febrero de 2003. http://elpais. com/diario/2003/02/16/internacional/1045350001_850215.html, consultado el 25.06.2014.

Declaración Universal de los Derechos Humanos, 1948.

Del Viso Pabón, N., «Lealtades incómodas: argumentos y debates en torno a la presencia de España en Afganistán (2001-2009)», Relaciones Internacionales 13, 2010, 105-137.

- «España en Irak: 2.600 soldados, casi tres relevos, 11 muertos», El Mundo. 18 de abril de 2004. http://www.elmundo.es/elmundo/2004/04/18/espana/1082310065.html, consultado el 4.10.2016.

Habermas, J., La inclusión del otro, Barcelona, Paidós, 1999.

Hinojosa MarTínez, L. M., «Irak y Afganistán: una comparación desde el derecho internacional», Análisis del Real Instituto Elcano (ARI) 10, 2008, 1-11.

Grocio, H., On the Law of War and Peace, Canada, Batoche Books, 2001.

Kant, I., Sobre la paz perpetua, Madrid, Akal, 2011.

Maestre, A., «Pan o ideología: Podemos e IU apoyan la venta de barcos de guerra a Arabia Saudí», lamarea.com. 23 de febrero de 2016. http://www.lamarea.com/2016/02/23/pan-oideologia-podemos-e-iu-tambien-apoyan-la-venta-de-barcos-de-guerra-a-arabia-saudi/, consultado el 04.10.2016

Martín Rojo, L., «Discursos en guerra. Crónicas y humor político en torno a la ocupación de Irak», Discurso \& Sociedad 1 (4), 2007, 575-603.

Milgram, S., "Some Conditions of Obedience and Disobediency to Authority», Human Relations 18 (57), 1965, 57-76.

NoyA, J., «Irak en la opinión pública internacional», en Bardají (ed.), Irak: Reflexiones sobre una guerra, Real Instituto Elcano de Estudios Internacionales y Estratégicos, 2003, 55-68.

Rampton, S. \& Stauber, J., Weapons of Mass Deception, New York, Penguin, 2003.

Robinson, P., Just War in Comparative Perspective, England, Ashgate, 2003.

Sontag, S., Ante el dolor de los demás, Madrid, Suma de Letras, 2004.

Instituto de Filosofía, Universidad de Innsbruck

Noelia Bueno Gómez

noelia.bueno-gomez@uibk.ac.at

[Artículo aprobado para su publicación en diciembre de 2015]. 